\title{
The Harpham Roman Villa in Context: Insights from an Integrated Remote-Sensing Survey on the Yorkshire Wolds
}

\author{
By ELEANOR MAW
}

\begin{abstract}
This contribution presents the first overview of an integrated remote-sensing survey undertaken across Harpham Roman Villa, East Yorkshire, and its wider landscape setting. The survey revealed one of the largest Roman courtyard complexes in northern Britain, nestled within an impressive crossroads system that formed part of a multiphase 'ladder settlement'. The paper considers the impact of the results on both our understanding of this unique landscape and broader methodological approaches to the study of rural settlement in Roman Britain.
\end{abstract}

Keywords: Roman Britain; rural settlement; Roman villa; Harpham; Yorkshire Wolds; geophysical survey; aerial photography

$\mathrm{R}$ ecent research into the landscape of Roman Britain has moved beyond the traditional foci of urban centres, forts and villas. The wealth of excavation and survey data generated since the introduction of Planning Policy Guidance 16 has allowed programmes such as the Roman Rural Settlement Project to advance discussions beyond the consideration of isolated Roman 'villas'. ${ }^{1}$ This research has highlighted the significance of issues such as regional variation in rural settlement patterns and has compelled a shift towards considerations of wider landscape contexts. ${ }^{2}$ Despite this shift, however, there remains a persistent tendency to separate the 'villa' from its broader landscape setting - at worst contrasting villas with what consequently becomes the 'background' rural settlement patterns within which they are so often embedded. Far from simply contextualising the 'villa' against the 'background' of rural settlement, therefore, this study seeks to promote analyses of broader landscape dynamics. ${ }^{3}$ The work presented here builds upon that of Dominic Powlesland in the Vale of Pickering in deploying large-scale geophysical prospection and aerial photographic survey to better understand the complex relationships between villas and their broader environs. ${ }^{4}$ It also demonstrates the value of reinvestigating poorly understood sites such as the Harpham Roman villa via an integrated remote-sensing approach.

\section{THE TWENTIETH-CENTURY EXCAVATIONS AT HARPHAM VILLA}

Located in 1904, initial excavations of the Harpham villa were conducted by the Reverend C.V. Collier, assisted by the first curator of the Hull Municipal Museum, Mr T. Sheppard. ${ }^{5}$ Their campaign resulted in the complete excavation of three rooms, each containing partially intact mosaic floors that were removed

$1 \quad$ Smith et al. 2016; 2018; Allen et al. 2017; for other influential projects, see, for example, Taylor 2007; Roymans and Derks 2011.

2 For example, Taylor 2007; Millett 2016.

3 The data presented here are a product of work undertaken as part of the author's $\mathrm{PhD}$ research, supervised by Martin Millett, University of Cambridge.

$4 \quad$ Powlesland et al. 1997; Powlesland 2008; 2014.

5 Collier 1905; 1907; Sheppard 1905.

(C) The Author(s), 2021. Published by Cambridge University Press on behalf of The Society for the Promotion of Roman Studies. This is an Open Access article, distributed under the terms of the Creative Commons Attribution-NonCommercial-ShareAlike licence (http://creativecommons.org/licenses/by-nc-sa/4.0/), which permits non-commercial re-use, distribution, and reproduction in any medium, provided the same Creative Commons licence is included and the original work is properly cited. The written permission of Cambridge University Press must be obtained for commercial re-use. 
to the Hull Municipal Museum for conservation (FIG. 1, 1-3). ${ }^{6}$ Objects found in association with two of the three mosaics include a series of third-century coins, while assorted ceramics, building materials, painted wall-plaster, metal fragments and significant quantities of shell and animal bone were recovered from across the site. ${ }^{7}$ Collier noted that several fragments of wall-plaster displayed evidence of redecoration. ${ }^{8}$ The plan of the building was difficult to determine due to the majority of the sandstone walls having been robbed out. ${ }^{9}$ Beyond the main villa building, evidence of a hypocaust was uncovered to the south-east, alongside evidence for building foundations in numerous test pits opened across the site. Unfortunately, no plan was made detailing their locations.

A second, more extensive campaign of excavations was conducted almost half a century later under the direction of the Bridlington Augustinian Society, in the early 1950s. ${ }^{10}$ The majority of this work, however, has never been published. The recent discovery of a notebook probably belonging to the supervising archaeologist, Mr C. Pilling, has made it possible to make sense of a limited number of sketch plans that survive in the project archive and to offer a tentative date for some of the features recorded. ${ }^{11}$ Having located the rooms excavated by Collier and Sheppard through the use of aerial photographs, Pilling - assisted principally by E. Mellor, C. Grantham and E. Grantham - proceeded to reveal the remains of an 'E'-shaped villa. ${ }^{12}$ Despite the limited preservation of the stone walls, these more extensive excavations enabled a more complete reconstruction of the villa plan based on intact floor surfaces (FIG. 1). Six further rooms were identified, all containing evidence of mosaic pavements (A-F). Pavements $\mathrm{D}, \mathrm{E}$ and $\mathrm{F}$ were recorded in situ, ${ }^{13}$ with the excavator noting that these floors and rooms were at a higher level than other parts of the villa, apparently because they were built over earlier structures. ${ }^{14}$ Further remains of structures were uncovered to the north, north-west and south-east of the central villa building. These included a hexagonal structure interpreted as a 'workshop', with associated finds including nails, horse trappings, oyster and limpet shells, amphora sherds and Crambeck and Throlam ware, ${ }^{15}$ remains of a hypocaust and tiled surface approximately $10 \mathrm{~m}$ to the north of the villa and two areas of rough flooring c. $20 \mathrm{~m}$ to the south and south-east (FIG. 1). Evidence was recorded of an earlier structure under the northern wing of the villa, which was filled with rubble, tile and painted wall-plaster fragments. In addition to the excavation of these structures, two trenches projecting north and south were opened from each end of the villa building to establish the limits of the site. These trenches identified two large ditches running approximately east-west to both the north and south of the villa (FIG. 1). They were similar in size, with each recorded as c. $2.7 \mathrm{~m}$ wide and c. $1.5 \mathrm{~m}$ deep. Ceramic material, metalwork moulds, crucibles, painted wall-plaster and sandstone tiles were recovered from the northern ditch and partially documented. ${ }^{16}$ Pilling also refers to ceramic material being excavated from the southern ditch; however, records of this material are yet to be identified. The northern ditch appears to have had a wall running roughly parallel along part of its southern edge, and this was interpreted as contemporary. ${ }^{17}$ Beyond their relative positions, the relationship between this ditch and wall was not recorded. Localised fieldwalking was also undertaken, and identified a concentration of Huntcliff ware ${ }^{18}$ to the east of the villa (FIG. 1). The objects recovered during these excavations were incorporated into the Granthams' Museum collection, now held by local archaeologist Peter Mackey.

\footnotetext{
For a comprehensive overview of the mosaics, see Neal and Cosh 2002.

Sheppard 1905.

Collier 1905, 218-19

Sheppard 1905.

10 Wright 1951; Mellor 1952.

11 Pilling unpublished field notes, Hull and East Riding Museum (HERM) archive. Access to the archive material was made possible through the generous assistance of Paula Gentil, Curator of Archaeology at the Hull and East Riding

12 Mellor 1952.

13 Mellor 1952, 117.

14 Pilling unpublished field notes, HERM archive.

15 Unpublished Harpham Project manuscript, HERM archive.

16 Unpublished Harpham Project archive, HERM.

17 Pilling unpublished field notes, HERM archive.

18 Today more commonly referred to as Huntcliff-type ceramics; see Hornsby et al. 1912.
} Museum. 


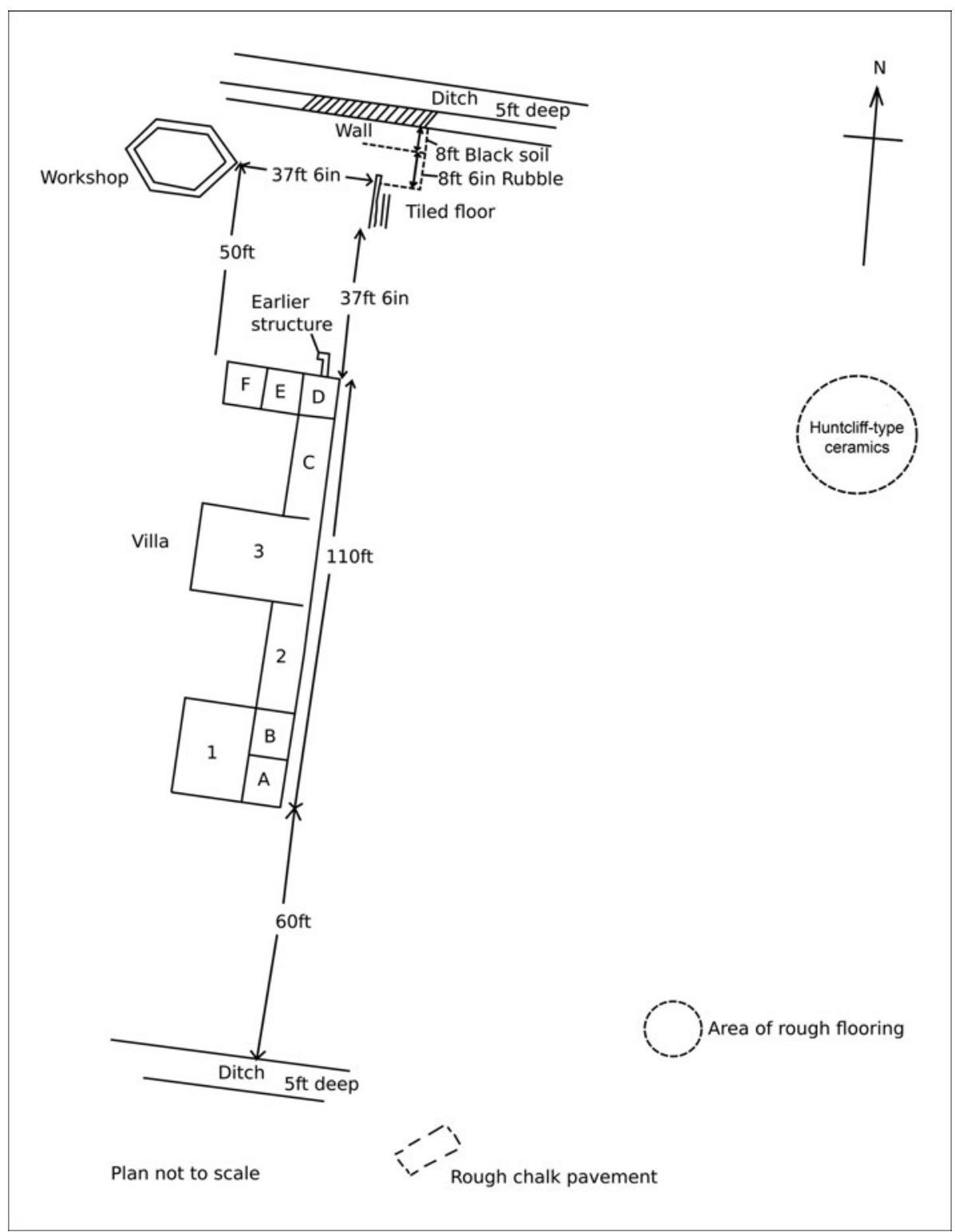

FIG. 1. Composite plan of the twentieth-century excavations (redrawn from unpublished material in the Harpham Project archive, Hull and East Riding Museum).

Despite the limitations of the twentieth-century excavation records, a tentative dating of the structures and enclosure ditches may still be offered. Based on the styles of the mosaic flooring, the schematics of the wall-painting, the associated ceramics and the numismatic evidence, the final redecoration of the 'E'-shaped villa appears to have been completed during the early fourth century. ${ }^{19}$ The terminus post

19 Wright $1951,126$. 
quem of the mosaic pavements can be placed securely at A.D. 305, due to the recovery of a coin of Constantius Chlorus, in almost mint condition, from the cement beneath pavement A. ${ }^{20}$ Although no comparable dating evidence was found in relation to the other pavements, their styles are all considered consistent with the early fourth century A.D. ${ }^{21}$ The evidence of earlier stone structures beneath both the central room and the northern wing of the 'E'-shaped building clearly indicates a multiphase Roman occupation of the site. Beyond the principal villa structure, brooch moulds recovered from the ditch to the north may point to the enclosure's occupation from as early as the second century A.D., with further material accumulating through to at least the fourth century. ${ }^{22}$ A piece of Parisian ware found within the 'workshop' structure was dated tentatively to the late first or early second century A.D. ${ }^{23}$

\section{THE 2019 GEOPHYSICAL SURVEY}

Over three weeks in September 2019, a gradiometry survey covering 120 ha of agricultural land between the villages of Kilham and Burton Agnes was conducted. The results highlight more than 6,000 archaeological features, and transform what was once understood as an isolated Roman villa building into an expansive courtyard complex at the heart of a densely populated and dynamic multi-period landscape (FIGS 2 and 3). Data collection was achieved using a bespoke, quad-drawn gradiometry cart array which utilised both Foerster and Leica instrumentation (property of the Landscape Research Centre) and was designed by the author in collaboration with Dominic Powlesland. ${ }^{24}$

It is immediately apparent that the main villa and its associated enclosure both evolved from, and are part of, a more intricate multiphase 'ladder settlement'. The villa complex is positioned within the north-eastern junction of a previously unidentified crossroads, created by two substantial, north-south and east-west, trackways (FIG. 4; for clearer illustration of the villa location, see FIG. 7). Aerial photographic evidence demonstrates that these trackways were part of a substantial network and provided access to several major routeways (FIG. 5), including the conjectured Roman road M810 to the site's north, which likely linked Eboricum to a suspected port, which has presumably been consumed by coastal erosion, to the east of modern-day Bridlington. ${ }^{25}$ The trajectory of the east-west trackway is more difficult to interpret, but it probably linked into a similar network conveying travellers east towards the coast and west into the neighbouring dry valley. Concentrated activity, including over 90 enclosures, is visible on either side of these trackways, revealing a hitherto unrecognised section of the region's Iron Age and Romano-British 'ladder settlement'. ${ }^{26}$ The majority of these enclosures contain evidence of structures, ranging from roundhouse gullies and post-hole groups to stone buildings of varying morphologies. While excavation is necessary to determine their date, it is clear from the differing alignments and the intersection of some of these enclosures that they illustrate multiple phases of occupation - with at least one distinct reorganisation of the landscape demonstrably connected to the establishment of the villa (discussed below). An extensive network of ditched field systems is also visible, dividing up vast blocks of land between the settlement at the survey's core and the outlying trackways (FIG. 5). Given its regional context, the earliest stages of this land division may date back as far as the Bronze Age, with several ditches displaying relationships with early dyke systems via surrounding cropmark evidence (FIG. 5). ${ }^{27}$

20 Pilling unpublished field notes, HERM archive.

21 Neal and Cosh 2002, 339; Smith 2005.

22 Evidence from the HERM archive, further supported by a brooch of similar style recovered close to the main villa building; see Brewster 1958, 54.

23 Pilling unpublished field notes, HERM; Corder 1958, 50.

24 This collaboration was enabled by a generous grant awarded by the Faculty of Classics, University of Cambridge.

25 See Margary 1973.

26 So named due to the characteristic rung-like appearance of their enclosures positioned either side of trackways and/or boundaries. For general discussion, see Stoertz 1997; Atha 2005; Fenton-Thomas 2005; Ferraby et al. 2017.

27 For comprehensive discussion of early land division on the Yorkshire Wolds, see Stoertz 1997; Fenton-Thomas 2003; Dent 2010; Giles 2012; Ferraby et al. 2017. 


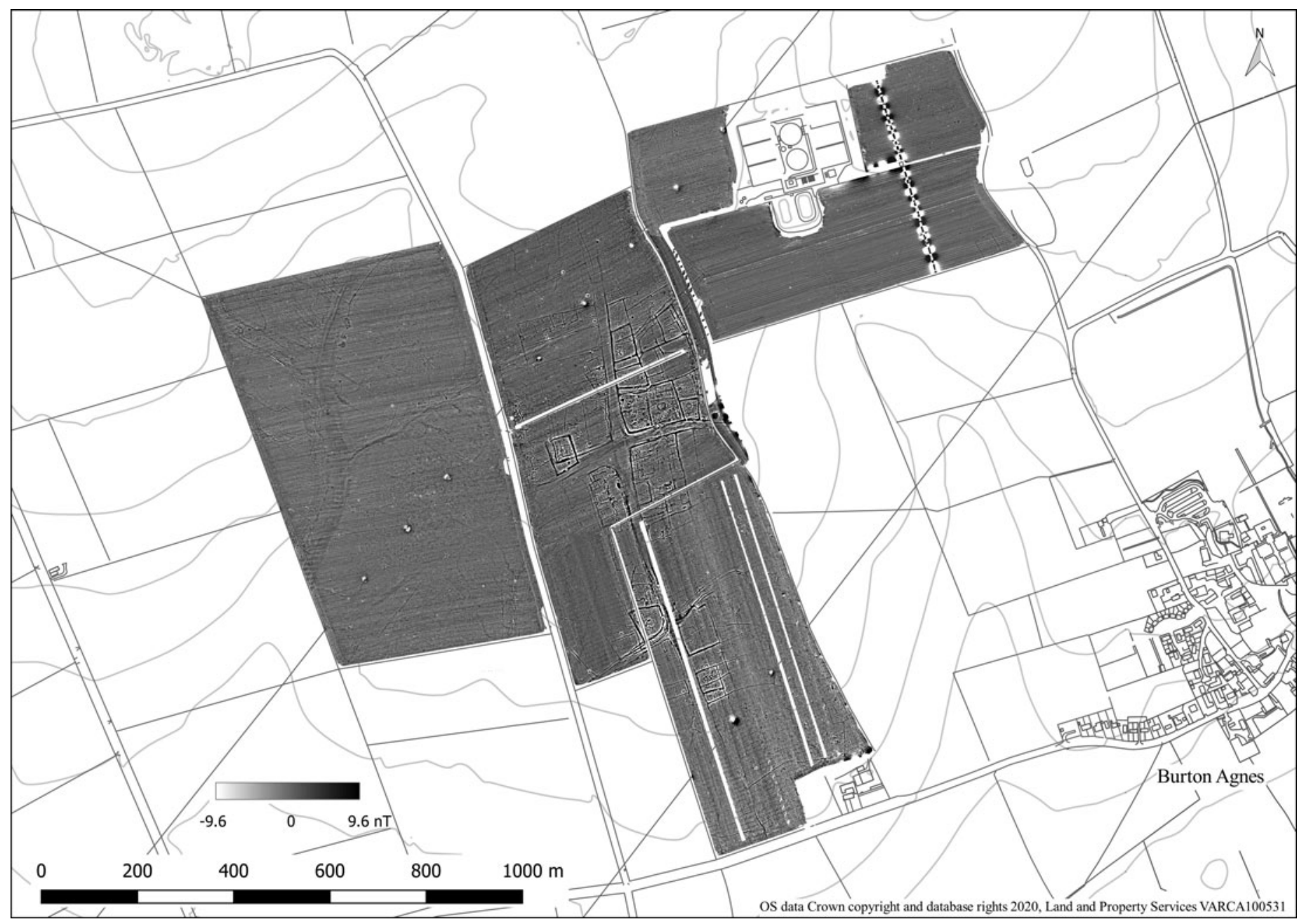

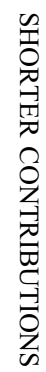




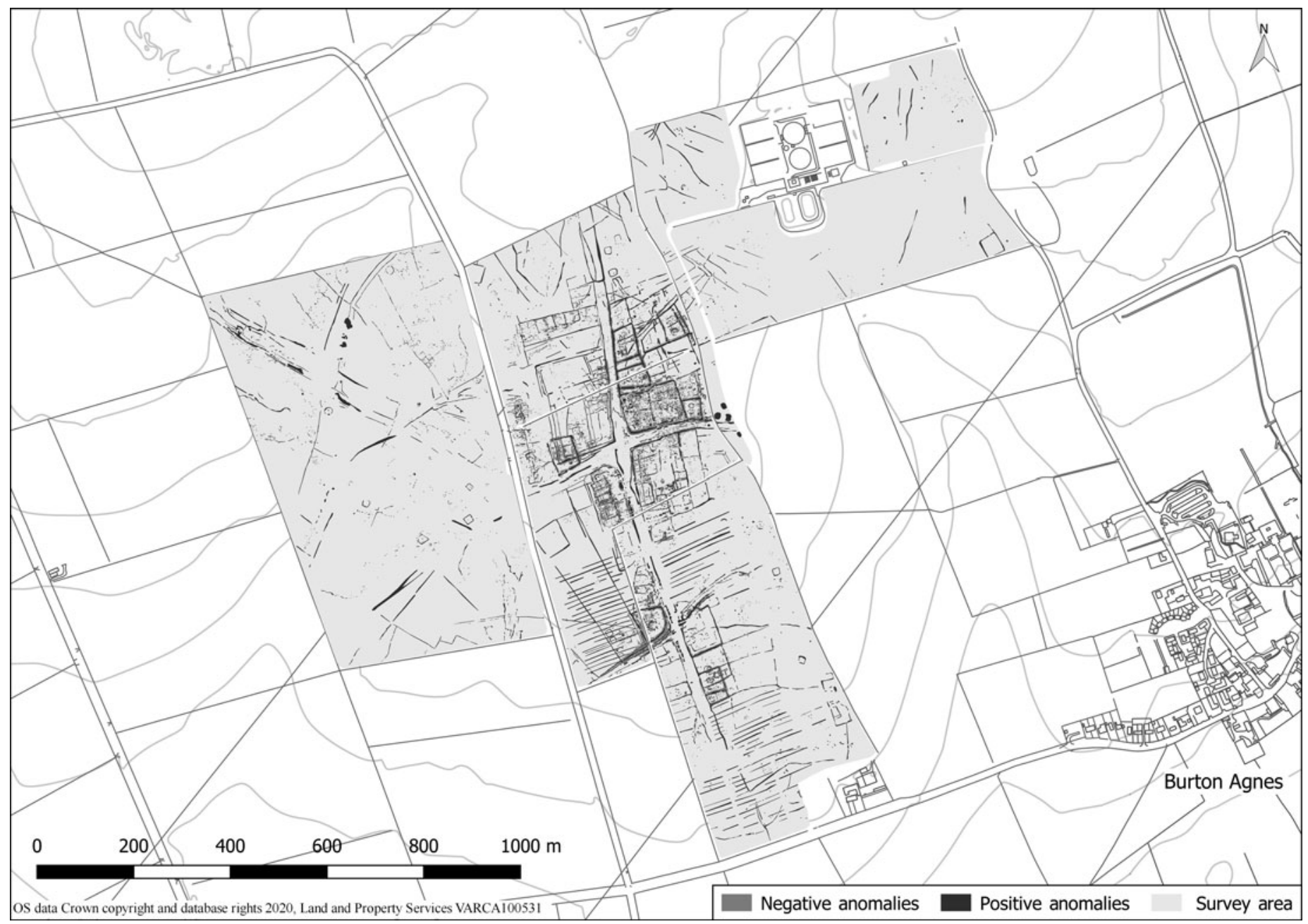

FIG. 3. Archaeological anomalies identified during the gradiometry survey of Harpham, East Yorkshire. 


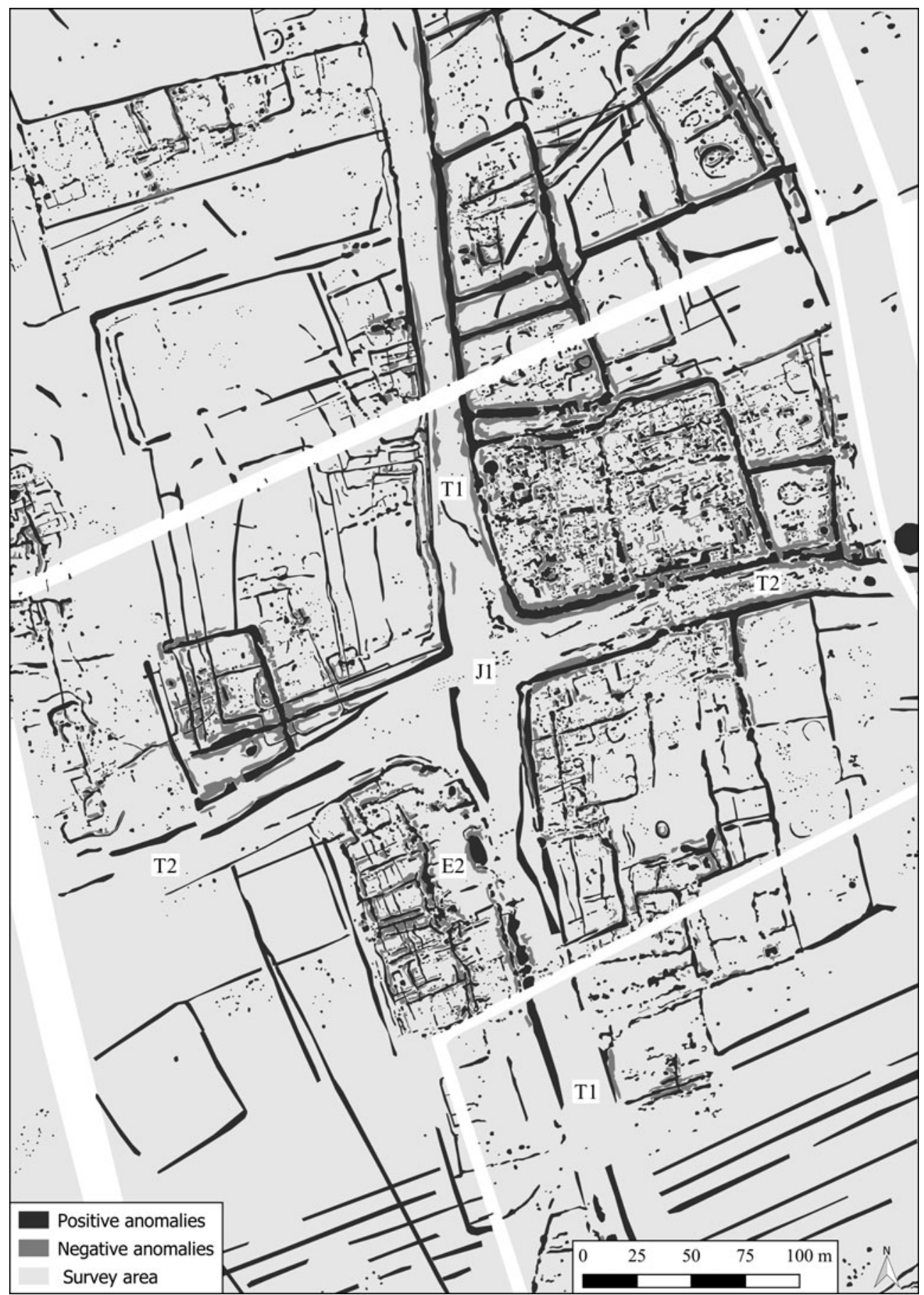

FIG. 4. The multiphase 'ladder settlement' crossroads, with the Harpham villa complex in the north-eastern quadrant. 


\section{THE SETTLEMENT}

Through a detailed analysis of the magnetic anomalies alongside the twentieth-century excavation records and their broader aerial photographic context, a tentative phasing of the 'ladder settlement' encompassing the Roman villa may be offered. Respected by the majority of subsequent archaeological features, it is clear that the north-south and east-west trackways represent some of the earliest features of this landscape, related to the dyke systems noted above (FIGS 4 and 5, T1-T2). Beyond those creating this central junction, however, the faint trace of a possible ditched trackway is also visible entering the north-western part of the survey area, connecting to a triple-ditched causeway visible in the aerial photographic records just beyond the limits of the survey (FIG. 5, T3). Given their connection, it may represent the continuation of the causeway. A series of enclosures respecting the initial limits of these trackways may then be identified, likely representing the first stage of enclosed settlement (FIG. 6, Phase 1b). Notable within this phase is the establishment of a significant rectilinear enclosure along the (initial) northern limits of trackway T2 (FIG. 6, E1). The size and morphology of this enclosure are consistent with settlement enclosures identified elsewhere on the Wolds dating to the Iron Age or early Roman period. ${ }^{28}$ While the majority of the enclosures surrounding junction J1 appear domestic, those located within the south-western quadrant probably represent a series of interconnected livestock enclosures (FIG. 6, E2). The proposed second phase then sees the amalgamation of four enclosures to the north-east of the crossroads junction, alongside the erection of a series of stone structures (FIG. 7). The construction of several iterations of the villa during this second phase seems to have been accompanied by the reorientation and establishment of new field systems and enclosures (FIG. 7, E3-E6). This restructuring involved the delineation of new limits to both the northern and southern sides of the western half of trackway T2, where the previously curved edges of its junction with T1 were moved northwards to form an approximately 90-degree angle. The assigning of enclosures E3-E6 to the Roman period is predominantly based on their orientation being identical to that of the villa courtyard. Evidence of a third phase may be identified within the north-western quadrant of the crossroads, where a group of anomalies is seen likely cutting enclosures E1 and E3, and continuing to their west (FIG. 8, Phase 3). Given their morphology, they perhaps represent post-Roman activity, with several potential Grubenhäuser visible. ${ }^{29}$

\section{THE ROMAN VILLA}

The 'E'-shaped villa building as recorded by Mellor ${ }^{30}$ is now shown to be the western limit of a far more extensive villa courtyard complex. This compound, measuring $c .180$ by $70 \mathrm{~m}$, is stunningly revealed by the 2019 high-resolution survey - displaying only limited impact from the disturbances of either previous excavation or the prolonged agricultural exploitation of this landscape (FIG. 9). The fourth-century villa building (S1) is immediately recognisable owing to the semicircular apse along the western edge of its central room, which was tentatively added to Mellor's 1950s plan by David Neal and Stephen Cosh following analysis of aerial photographic evidence collected in $1981 .{ }^{31}$ As noted above, the construction of rectilinear stone structures within this area appears to have gone through a minimum of two separate phases. The first, integrating the faint traces of structures identified beneath the fourth-century ' $E$ '-shaped villa during the twentieth-century excavations, consists of five possible buildings (FIG. 9, S2-S6). Each of these appears to share a similar orientation, broadly consistent with that of the remaining Phase $1 \mathrm{~b}$ enclosure ditch which continued to surround this part of the settlement. ${ }^{32}$ Most notably, structure S2 appears to have been constructed halfway across a large roundhouse gully (R1) and shares an architectural plan similar to those of early villas excavated elsewhere in northern Britain. ${ }^{33}$ The positioning of initial villa buildings directly over earlier domestic structures is common where continuity of occupation between

Stoertz 1997, 49.

cf. Powlesland 2008, 172.

Mellor 1952.

Neal and Cosh 2002, 338.

As indicated by material excavated in 1952 and noted above: Pilling unpublished field notes, HERM archive.

cf. Beadlam villa, North Yorkshire: Neal 1996. 


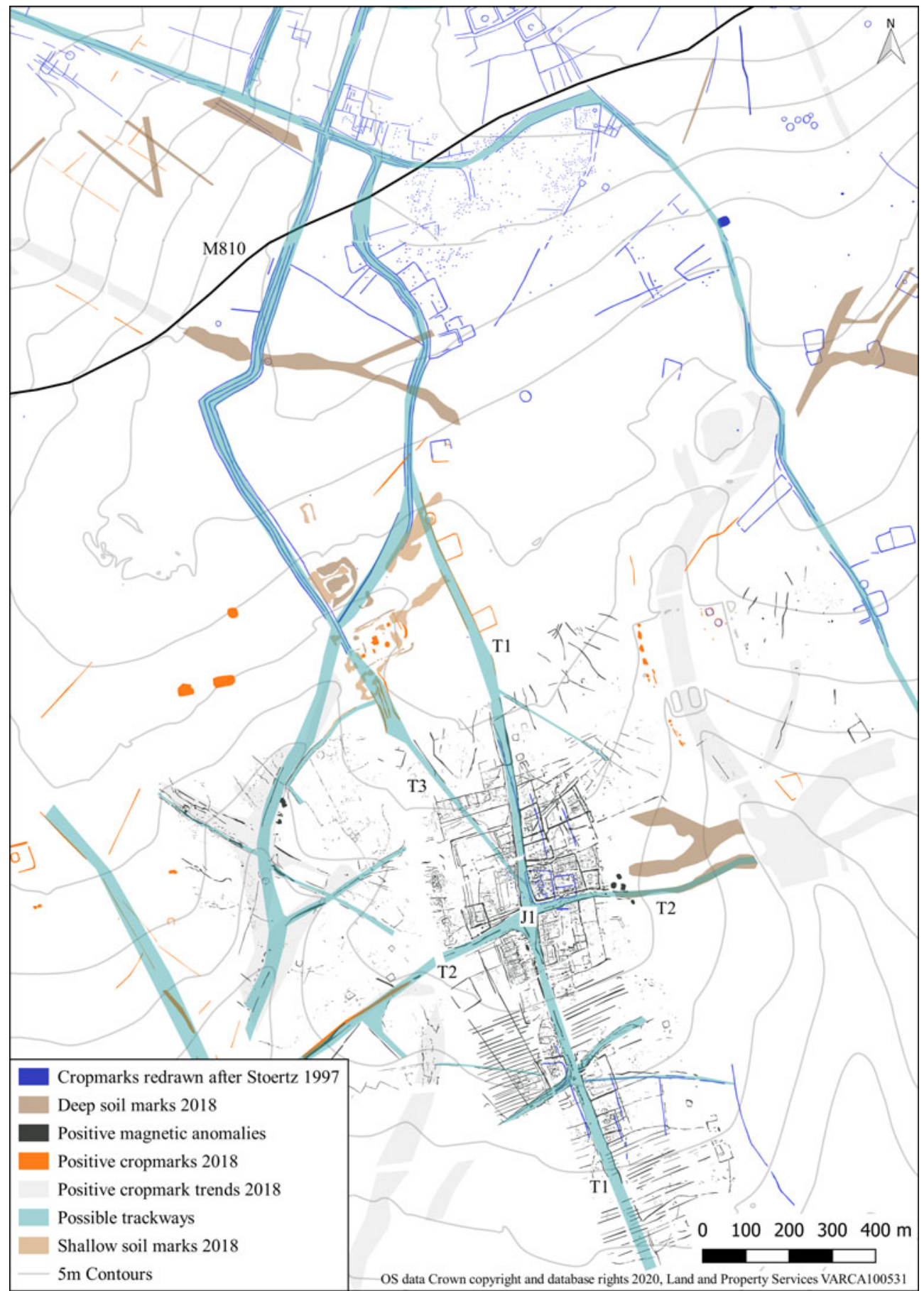

FIG. 5. Integrated aerial photographic evidence and gradiometry survey results for Harpham, East Yorkshire. 


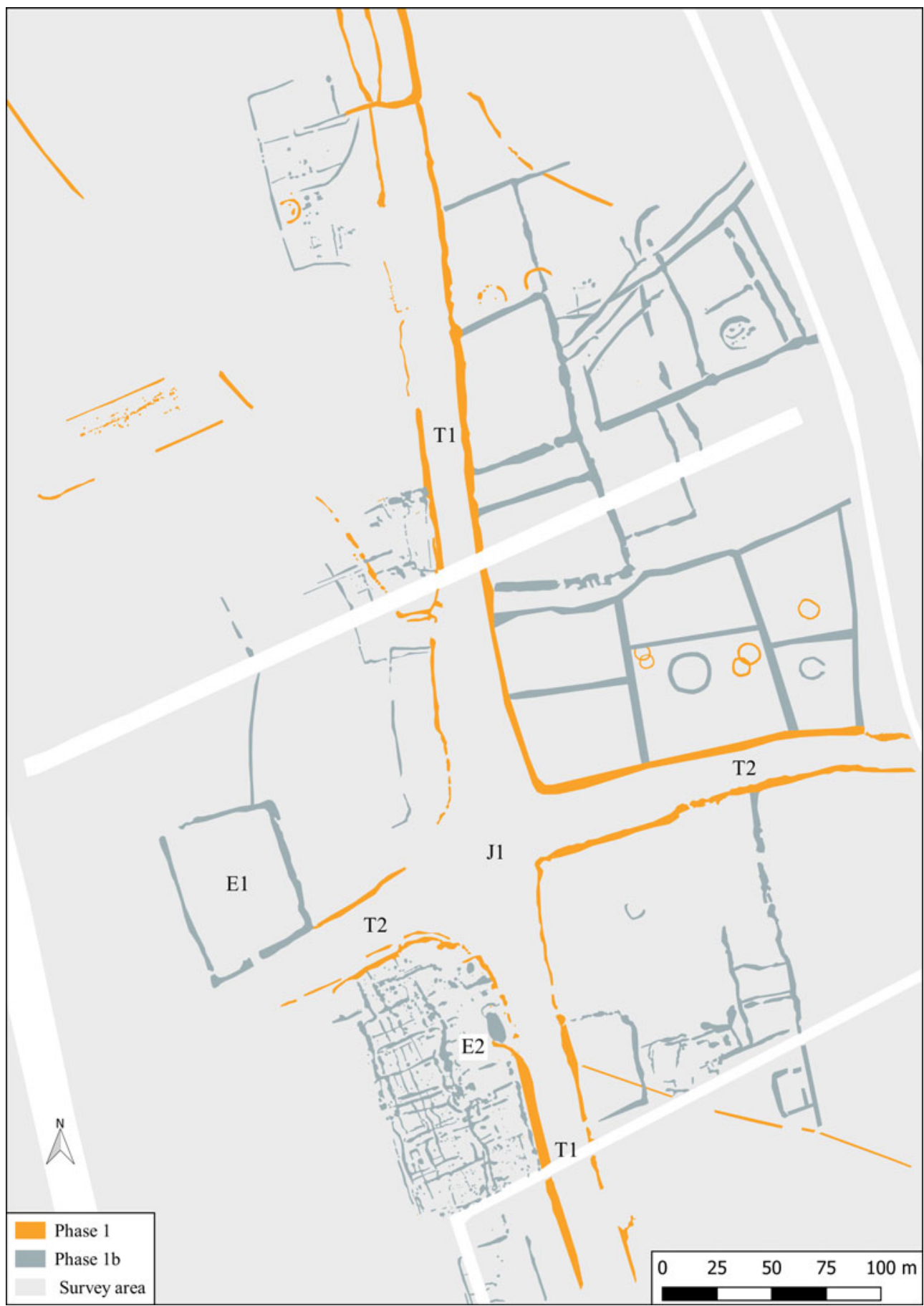

FIG. 6. Interpretation of the gradiometry survey results: proposed Phase $1 / 1 \mathrm{~b}$ features. 


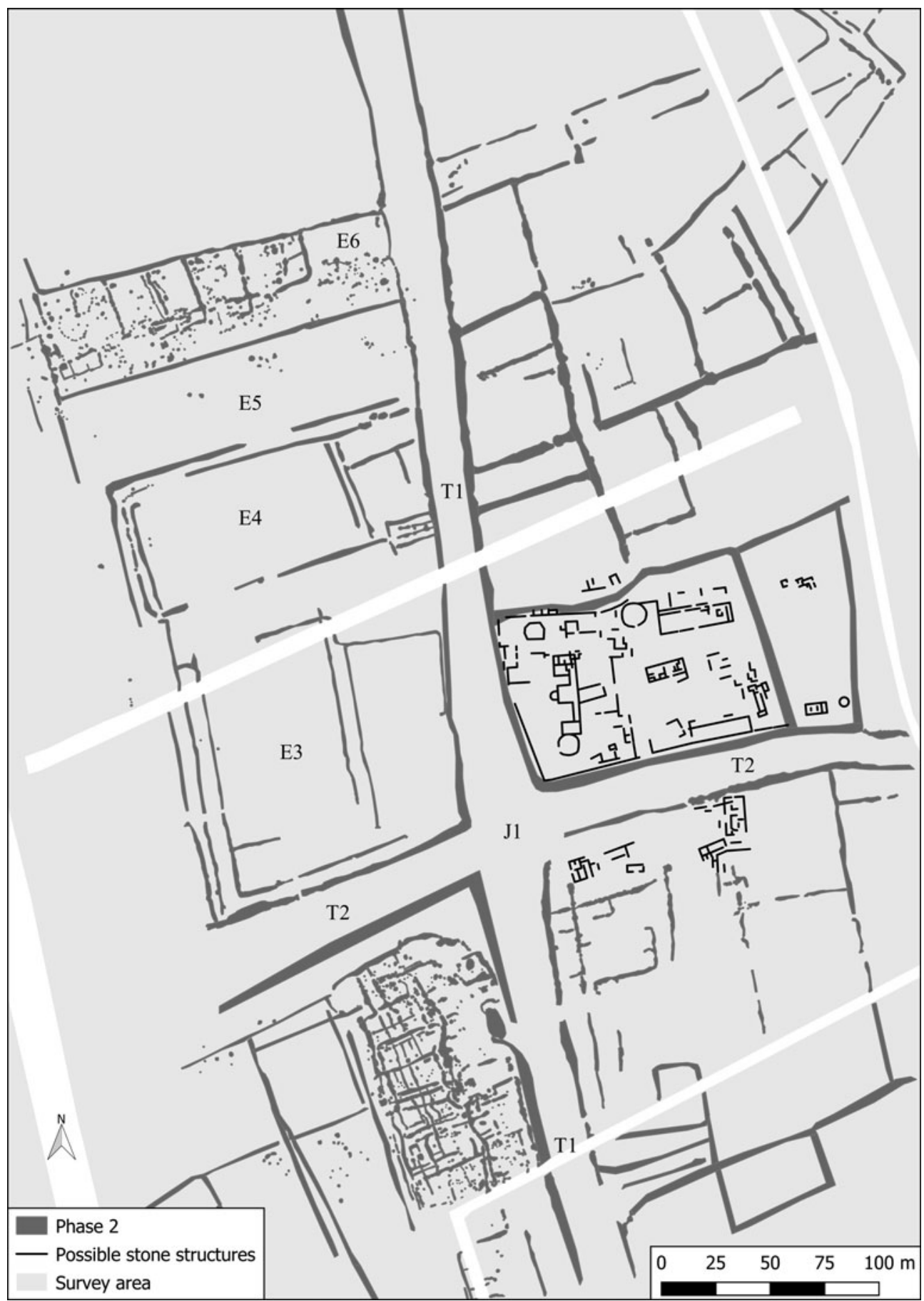

FIG. 7. Interpretation of the gradiometry survey results: proposed Phase 2 features. 


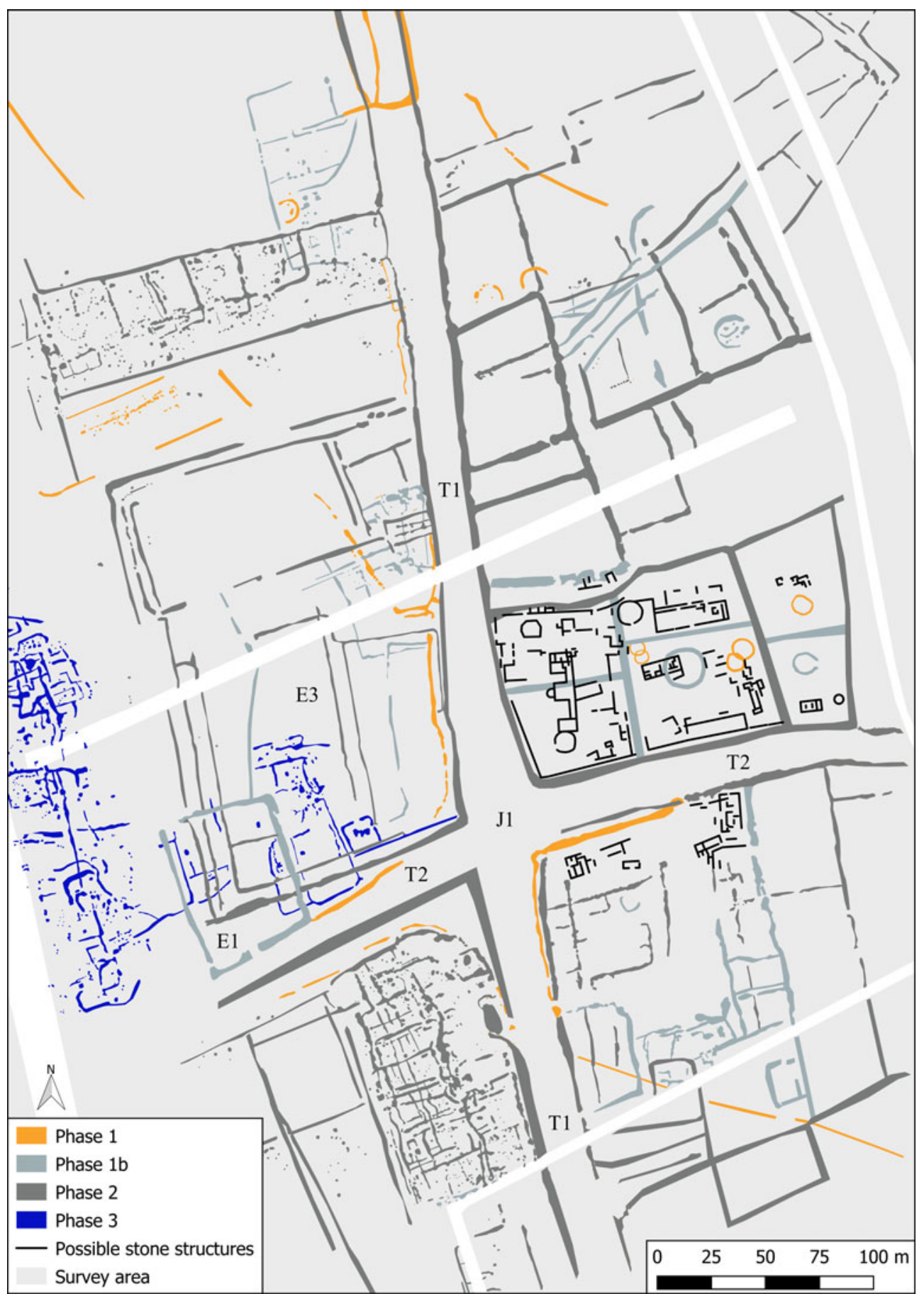

FIG. 8. Composite interpretation of the gradiometry survey results: proposed Phases 1-3 features. 


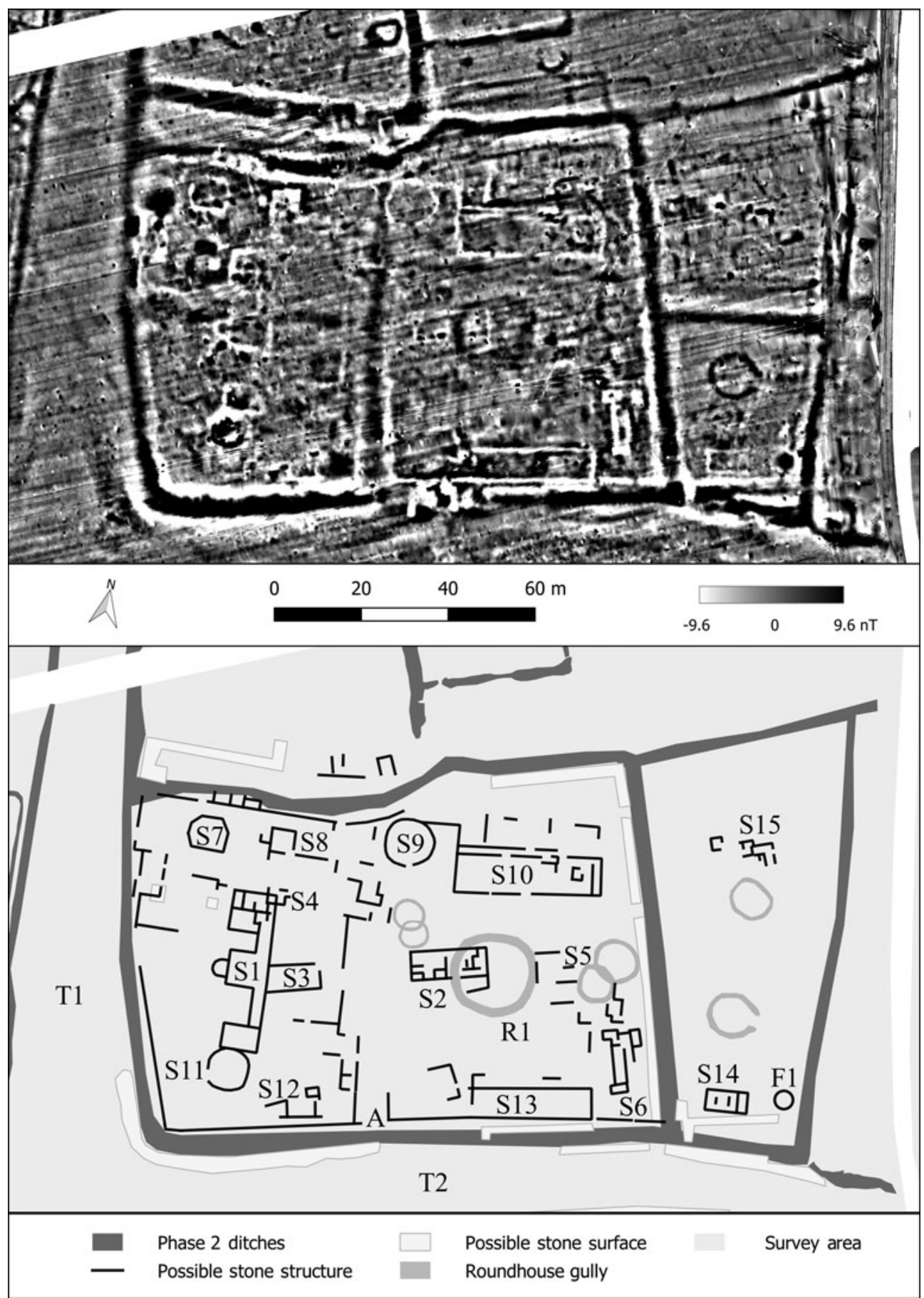

FIG. 9. Detail of the gradiometry survey results: the Harpham villa complex and interpretation of the stone structures identified. 
the Iron Age and the early Roman period occurs, and is evidenced elsewhere locally. ${ }^{34}$ It is possible, therefore, that this structure represents the primary stone structure constructed at the site, which was later superseded by $\mathrm{S} 1$ as the central residence. The style of S2 is consistent with the 'row type' of villa, which developed across Britain from the first century A.D. ${ }^{35}$ S3 and S4, which disappear beneath S1 and were partially excavated in the $1950 \mathrm{~s}$, must predate the fourth-century phase of the site, while material excavated from the possible 'workshop' (S7) also points to its use during an earlier phase. It is impossible to ascertain whether building S2 continued to be used following the construction of S1. Its demolition or conversion from a primary residence to an ancillary building cannot be determined without excavation. S6, located in the south-eastern corner of the enclosure and identified as a possible bath-house due to its architectural plan, displays a similar alignment to S2-S5. It is difficult to ascertain whether this is a consequence of the angle of the earlier enclosure ditch situated directly to its east, which was possibly in use throughout the Roman period.

The second proposed phase of the villa's development saw a further five buildings constructed along the northern and southern limits of the enclosure that were met at the western end by S1. This created what appears to have been a large courtyard complex with the most substantial structures, S10 and S13, located at the eastern end, furthest away from what may be assumed to be the primary domestic structure at this point (FIG. 9). Although their role as ancillary agricultural buildings cannot be ruled out, their monumental size may instead imply an expansion of the complex's domestic space - perhaps representing large halls. ${ }^{36}$ Particularly striking is the round stone structure (S9) located at the centre of those situated along the northern limits of the compound. Approximately $11 \mathrm{~m}$ in diameter, it is reminiscent of stone roundhouse buildings infrequently found either in association with or as part of rectilinear villa compounds. It may represent a further domestic structure within the enclosure, perhaps a direct replacement for roundhouse $\mathrm{R} 1$ or, alternatively, an agricultural building, such as a granary or threshing floor. ${ }^{37} \mathrm{~A}$ further round stone structure (S11) may be seen directly to the south of, and perhaps even attached to, the southern wing of excavated S1 (FIG. 9); given this relationship, it is likely domestic. Entry to the courtyard complex may have been achieved along the southern limits, where there appears to be a possible access point (A) from trackway T2. Two further stone structures (S14 and S15) are visible directly to the east of this complex. These are impossible to phase with any confidence, though S14 is reminiscent of an aisled hall building, and so may be a previously unidentified villa. A strong, circular magnetic anomaly to the east of this structure (F1) may represent a well.

\section{DISCUSSION}

The 2019 geophysical survey is the largest contiguous survey undertaken on the Yorkshire Wolds to date. ${ }^{38}$ Like so many 'villas' excavated in the earlier part of the twentieth century, our prior understanding of the Harpham villa was extremely limited. The results of this re-evaluation effectively demonstrate how the combination of an integrated remote-sensing approach with reassessment of previously unpublished archive material can significantly alter the perception of such sites. The results have radically changed our understanding of both the villa and its ancient environs. A once isolated structure at the heart of an empty landscape has been transformed into an imposing complex, intricately connected to the vibrant rural community within which it was situated. By revealing a complex array of settlement and land use evidently spanning a prolonged period, the results further illustrate the importance of Britain's varied prehistoric landscapes in shaping both later Roman settlement morphologies and broader land division. Such a level of detail is essential when attempting to form meaningful narratives about past landscapes. This is especially true when considering the underlying causes of regional variation, where even minor differences in patterns of, for example, settlement style and landscape organisation can demonstrably influence the evolution of these spaces for centuries following their establishment. In the case of the

See, for example, Rudston villa $4 \mathrm{~km}$ to the north: Stead 1980; Cousins et al. 2017.

Smith et al. 2016, 73. For typology, see Smith 1997.

cf. Thwing: Ferraby et al. 2017.

cf. Ditchley in Oxfordshire: Raleigh Radford 1936.

For other significant surveys on the Wolds, see Wrathmell 2012; Ferraby et al. 2017. 
Yorkshire Wolds, it is widely accepted that the first tangible division of the landscape took place in the Bronze Age, when large blocks of land were carved up by extensive systems of dykes, pit alignments and ditched causeways. ${ }^{39}$ As demonstrated above, many of these dykes and causeways subsequently formed the backbone of later Iron Age and Romano-British 'ladder settlements'. In some ways, therefore, the location of the Harpham villa site was partially determined centuries before the Roman Empire even existed. In allowing us to visualise this ever-evolving process of delineation, occupation and reorganisation, geophysical surveys on this scale can offer invaluable insight into these dynamic archaeological landscapes, which may otherwise remain poorly understood. Beyond the consideration of this specific landscape, by exploring the impact of Romano-British villas on pre-existing settlement sites more widely, the Harpham results may also be used to illustrate the tension between local settlement tradition and incorporation into the Empire - a key contributor to regional variation. Through the subtle reorganisation of the landscape, it may be argued that occupants of the imposing villa complex - most likely members of the same community that had worked this land for centuries - were attempting to tread the fine line between integration into an increasingly 'Roman' Britain and preservation of the traditions of previous generations.

\section{ACKNOWLEDGEMENTS}

I am most grateful to Martin Millett, for his constructive comments on an earlier version of this contribution, and to Paula Gentil of the Hull and East Riding Museum, for making it possible for me to consult the Harpham Project archive. I am extremely thankful to Sir Charles Legard and Simon Cunliffe-Lister for permitting me access to the Scampston and Burton Agnes Estates, respectively, and to Mr Robinson, $\mathrm{Mr}$ W. Legard and Mr Reed for supporting the work. Historic England kindly granted a Section 42 Licence to survey the scheduled monument area. Emma Brownlee, Gina Edney and Esther Laver assisted with data collection, which was generously supported by Cambridge University's Faculty of Classics and the Landscape Research Centre. I am especially thankful to Marthe Klöcking, Joanna Lawrence, Emily Wright and the anonymous reviewer for their thoughts and comments throughout the preparation of this contribution. Any remaining issues or errors are entirely my own.

University of Cambridge

ejmaw76@googlemail.com

doi:10.1017/S0068113X21000106

\section{BIBLIOGRAPHY}

Allen, M., Lodwick, L., Brindle, T., Fulford M., and Smith, A. 2017: The Rural Economy of Roman Britain, Britannia Monograph 30, London

Atha, M. 2005: 'Brickworks and ladders: exploring intra-regional diversity in the enclosed landscapes of the Parisi' in J. Bruhn, B. Croxford and D. Grigoropoulos (eds), Proceedings of the Fourteenth Annual Theoretical Roman Archaeology Conference, Oxford, 97-108

Brewster, T.C.M. 1958: 'Four finds from East Yorkshire', Yorkshire Archaeological Journal 39, 53-7

Collier, C.V. 1905: 'Thursday, 9th February, 1905', Proceedings of the Society of Antiquaries of London 20.1, 215-20

Collier, C.V. 1907: 'The Roman remains at Harpham', Transactions of the East Riding Antiquarian Society 13.2, 141-52

Corder, P. 1958: 'Parisian ware', Yorkshire Archaeological Journal 39, 48-52

Cousins, E., Maw, E., and Millett, M. 2017: 'The Rudston villa and its landscape', in R. Ferraby, P. Johnson, M. Millett and L. Wallace (eds), Thwing, Rudston and the Roman-Period Exploitation of the Yorkshire Wolds, Yorkshire Archaeological Report 8, Leeds, 235-67 
Dent, J.S. 2010: The Iron Age in East Yorkshire: An Analysis of the Later Prehistoric Monuments of the Yorkshire Wolds and the Culture which Marked their Final Phase, British Archaeological Reports British Series 508, Oxford

Fenton-Thomas, C. 2003: Later Prehistoric and Early Historic Landscapes on the Yorkshire Wolds, British Archaeological Reports British Series 350, Oxford

Fenton-Thomas, C. 2005: The Forgotten Landscapes of the Yorkshire Wolds, Stroud

Ferraby, R., Johnson, P., Millett, M., and Wallace, L. (eds) 2017: Thwing, Rudston and the Roman-Period Exploitation of the Yorkshire Wolds, Yorkshire Archaeological Report 8, Leeds

Giles, M. 2012: A Forged Glamour: Landscape, Identity and Material Culture in the Iron Age, Oxford

Hornsby, W., Stanton, R., Craster, H.H.E., Hill, G.F., Newbold, P., Macdonald, G., Keith, A., and Marshall G.S. 1912: 'The Roman fort at Huntcliff near Saltburn', Journal of Roman Studies 2, 215-32

Margary, I.D. 1973: Roman Roads in Britain (3rd edition), London

Mellor, E. 1952: 'The Harpham villa', Yorkshire Archaeological Journal 38, 117-18

Millett, M. 2016: “'By small things revealed": rural settlement and society', in M. Millett, L. Revell and A. Moore (eds), The Oxford Handbook of Roman Britain, Oxford, 699-719

Millett, M., Revell, L., and Moore, A. (eds) 2016: The Oxford Handbook of Roman Britain, Oxford

Neal, D. 1996: Excavations on the Roman Villa at Beadlam, Yorkshire, Yorkshire Archaeological Report 2, Leeds

Neal, D.S., and Cosh, S.R. 2002: Roman Mosaics of Britain 1: Northern Britain, Incorporating the Midlands and East Anglia, London

Powlesland, D. 2008: 'Why bother? Largescale geomagnetic survey and the quest for "Real Archaeology"', in S. Campana and S. Piro (eds), Seeing the Unseen: Geophysics and Landscape Archaeology, London, 167-82

Powlesland, D. 2014: 'The Iron Age to Anglo-Saxon landscape of the Vale of Pickering', in D.J. Breeze (ed.), The Impact of Rome on the British Countryside: A Conference Organized by the Royal Archaeological Institute, Chester, 11-13 October 2013, London, 12-16

Powlesland, D., Lyall, J., and Donoghue, D. 1997: 'Enhancing the record through remote sensing: the application and integration of multi-sensor, non-invasive remote sensing techniques for the enhancement of the Sites and Monuments Record: Heslerton Parish Project, N. Yorkshire, England' Internet Archaeology 2, http://intarch.ac.uk/journal/issue2/pld/index.html (accessed June 2021)

Raleigh Radford, C.A. 1936: 'The Roman villa at Ditchley, Oxon.', Oxoniensia 1, 24-69

Roymans, N., and Derks, T. (eds) 2011: Villas in the Roman North: Economy, Culture and Lifestyles, Amsterdam

Sheppard, T. 1905: 'Roman villa at Harpham, East Yorkshire' Hull Museum Publications 23, 173-9

Smith, A., Allen, M., Brindle, T., and Fulford, M. 2016: The Rural Settlement of Roman Britain, Britannia Monograph 29, London

Smith, A., Allen, M., Brindle, T., Fulford, M., Lodwick, L., and Rohnbogner, A. 2018: Life and Death in the Countryside of Roman Britain, Britannia Monograph 31, London

Smith, D.J. 2005: Roman Mosaics at Hull (3rd edition), Hull

Smith, J.T. 1997: Roman Villas: A Study in Social Structure, London

Stead, I.M. 1980: Rudston Roman Villa, Leeds

Stoertz, C. 1997: Ancient Landscapes of the Yorkshire Wolds, Swindon

Taylor, J. 2007: An Atlas of Roman Rural Settlement in England, Council for British Archaeology Research Report 151, York

Wrathmell, S. (ed.) 2012: Wharram 13: A History of Wharram and its Neighbours, York

Wright, R.P. 1951: 'Roman Britain in 1950 I: sites explored', Journal of Roman Studies 41, 126 